\title{
Competition between maize and Echinochloa crus-galli analysed by a hyperbolic regression model
}

\author{
By C. J. T. SPITTERS*, M. J. KROPFF and W. de GROOT** \\ Department of Theoretical Production Ecology, Agricultural University, \\ P.O. Box 430, 6700 AK Wageningen, The Netherlands \\ **Centre for Agrobiological Research, P.O. Box 14, \\ 6700 AA Wageningen, The Netherlands
}

(Accepted 4 September 1989)

\begin{abstract}
Summary
Yield reduction of maize in relation to naturally established populations of Echinochloa crus-galli and Chenopodium album was studied in field experiments over 2 years in which the maize was grown at a wide range of weed densities. Both the crop and the weeds were harvested at intervals during the season. The competitive relations were described accurately by a model based on a hyperbolic relation between yield and plant density. The model can be linearised by considering the reciprocals of the average weight per plant. However, estimating the regression coefficients by linear regression introduced a severe bias due to heterogeneity of variances. Estimation was improved by applying non-linear regression, using a logarithmic transform of the yield equation. Fitted regressions were used to interpolate the yield data to standard weed densities. At a density of 100 Echinochloa plants $\mathrm{m}^{-2}$, maize yields were reduced by $8 \%$ and $82 \%$ in 1982 and 1983, respectively, illustrating the problems in generalising the results of one competition experiment to the other. Three possible fields of application of the competition model are discussed, i.e. adjustment of experimental plot yield for variation in weed population, prediction of expected crop yield losses, and prediction of long-term changes in weed seed populations.
\end{abstract}

\section{Introduction}

The main component of crop yield loss due to weeds is competition with the weeds for limiting resources. Analysis of crop-weed competition experiments and assessment of the effects of weed infestations on crop yield require quantitative models. There is extensive literature on quantitative analyses of plant competition, mainly directed towards a description of the effects at a single time using an empirical regression equation. Frequently an equation has been used which is based on a hyperbolic relationship between the yield and plant density of a species in monoculture (de Wit, 1960; Ogawa, 1960, cited by Suehiro \& Ogawa, 1980; Wright, 1981; Spitters, 1983a). More detailed expressions for the yield-density relationship have also led to more complicated equations for inter-specific competition (Watkinson, 1981, 1984; Spitters, 1983b). There have been several applications of these regression equations to the description of competition between crop and weeds: e.g. Rerkasem (1978), Elberse \& de Kruyf (1979), Spitters \& van den Bergh (1982), Håkansson (1983), Firbank, Manlove, Mortimer *Present address: Centre for Agrobiological Research, P.O. Box 14, 6700 AA Wageningen, The Netherlands (C) 1989 Association of Applied Biologists 
\& Putwain (1984), and Cousens (1985). The simple hyperbolic equation appears to give a good description for most situations. In this paper this simple form will therefore be applied.

The aim of the present paper is to analyse the response of maize yield to population density of the weed Echinochloa crus-galli (L.) P.B. (barnyard grass). Maize was grown at a wide range of plant densities of Echinochloa in the field and both crop and weed were harvested at several time intervals to study the seasonal course of the competitive relations. A second aim was to evaluate the use of the hyperbolic equation for the analysis of crop-weed interactions. The equation is therefore simplified to describe the situation where the crop is grown at constant density and special attention is paid to the statistical aspects of the estimation of the competition coefficients.

\section{Description of the model}

The hyperbolic yield-density equation and its extension to account for the presence of other, competing species will be briefly discussed, following the parameterisation used by Spitters $(1983 a)$. Thereafter, a simplified formula is derived for situations in which crop yield is considered at constant crop density but at varying weed densities.

\section{Intra-specific competition}

Competition between plants of the same species is characterised by the response of yield to plant density, which can often be described by a rectangular hyperbola (e.g. Holliday, 1960):

$$
\mathrm{Y}=\mathrm{N} /\left(\mathrm{b}_{\mathrm{o}}+\mathrm{b}_{\mathrm{c}} \mathrm{N}\right)
$$

where $\mathrm{Y}$ is the yield in $\mathrm{g} \mathrm{m}^{-2}, \mathrm{~N}$ the plant density in numbers $\mathrm{m}^{-2}$ and $\mathrm{b}_{\mathrm{o}}$ and $\mathrm{b}_{\mathrm{c}}$ are parameters. This implies a linear relationship between the reciprocal of the average weight per plant $(1 / \mathrm{W})$ and plant density $(\mathrm{N})$ :

$$
1 / \mathrm{W}=\mathrm{N} / \mathrm{Y}=\mathrm{b}_{\mathrm{o}}+\mathrm{b}_{\mathrm{c}} \mathrm{N}
$$

where $\mathrm{W}$ is in $g$ plant ${ }^{-1}$. The parameters $b_{o}$ and $b_{c}$ represent the intercept and slope of the linear relationship. When $N$ approaches zero, $1 / \mathrm{W}$ approaches $b_{0}$. Thus $1 / b_{0}$ is the extrapolated apparent weight of an isolated plant. The slope $b_{c}\left(\mathrm{~m}^{2} \mathrm{~g}^{-1}\right)$ measures how $1 / \mathrm{W}$ increases, and thus how the per-plant weight $\mathrm{W}$ decreases with any plant added to the population. The ratio $b_{c} / b_{o}$ expresses this increase relative to its value without competition so that it is a measure of intra-specific competition. The quantity $1 / b_{c}$ is the asymptote of the relation between $\mathrm{Y}$ and $\mathrm{N}$ (eqn 1), and hence measures the apparent maximum yield per unit area $\left(\mathrm{g} \mathrm{m}^{-2}\right)$.

\section{Inter-specific competition}

As $1 / \mathrm{W}$ is affected additively by adding plants of the same species (eqn 2), it can be assumed that adding plants of another species also affects 1/W additively. Hence, the reciprocal perplant weight of the crop in mixture with weeds can be expressed in the multiple linear regression form:

$$
\begin{gathered}
1 / \mathrm{W}_{\mathrm{c}}=\mathrm{b}_{\mathrm{co}}+\mathrm{b}_{\mathrm{cc}} \mathrm{N}_{\mathrm{c}}+\mathrm{b}_{\mathrm{cw}} \mathrm{N}_{\mathrm{w}} \\
\text { or } \\
\mathrm{Y}_{\mathrm{c}}=\mathrm{N}_{\mathrm{c}} \mathrm{W}_{\mathrm{c}}=\mathrm{N}_{\mathrm{c}} /\left(\mathrm{b}_{\mathrm{co}}+\mathrm{b}_{\mathrm{cc}} \mathrm{N}_{\mathrm{c}}+\mathrm{b}_{\mathrm{cw}} \mathrm{N}_{\mathrm{w}}\right)
\end{gathered}
$$


in which $b_{c w} N_{w}=b_{c 1} N_{1}+\ldots+b_{c n} N_{n}$ for the weed species $1, \ldots n$. The first subscript of the regression coefficients denotes the species for which yield is considered, while the second subscript points to the associated species (c and w refer to crop and weed, respectively). The coefficient $b_{c c}$ measures the effect of intra-specific competition within the crop, whereas $b_{c w}$ quantifies the effect of inter-specific competition of the weed on the crop. Adding one plant of the crop has an equal effect on $1 / \mathrm{W}_{\mathrm{c}}$ as adding $\mathrm{b}_{\mathrm{cc}} / \mathrm{b}_{\mathrm{cw}}$ weed plants. Thus the ratio $\mathrm{b}_{\mathrm{cc}} / \mathrm{b}_{\mathrm{cw}}$ measures the relative competitive ability of the crop with respect to the weed.

In general, the crop is grown at constant plant density. This simplifies equation $(3 a)$ for the reciprocal per-plant weight of the crop $\left(1 / \mathrm{W}_{c}\right)$ to:

$$
1 / \mathrm{W}_{\mathrm{c}}=\mathrm{a}_{\mathrm{o}}+\mathrm{b}_{\mathrm{w}} \mathrm{N}_{\mathrm{w}} \text { or } \mathrm{Y}_{\mathrm{c}}=\mathrm{N}_{\mathrm{c}} /\left(\mathrm{a}_{\mathrm{o}}+\mathrm{b}_{\mathrm{w}} \mathrm{N}_{\mathrm{w}}\right)
$$

where $a_{o}=b_{c o}+b_{c c} N_{c}$. Expressing the yield of the weedy crop per unit area as a proportion of its yield without weeds gives:

$$
\mathrm{Y}_{\text {weedy }} / \mathrm{Y}_{\text {weed-free }}=\mathrm{a}_{\mathrm{o}} /\left(\mathrm{a}_{\mathrm{o}}+\mathrm{b}_{\mathrm{w}} \mathrm{N}_{\mathrm{w}}\right)=1 /\left(1+\mathrm{N}_{\mathrm{w}} \mathrm{b}_{\mathrm{w}} / \mathrm{a}_{\mathrm{o}}\right)
$$

The relative competitive ability of the weed with respect to the crop is measured by $b_{w} / a_{o}$, which characterises the fractional yield loss caused by the first weed plant added to the crop population. This can be shown by taking the derivative to $\mathrm{N}_{\mathrm{w}}$ of equation (5), which approaches $-b_{w} / a_{o}$ when $N_{w}$ approaches zero (initial slope of equation (5)). The yield loss caused by each additional weed plant diminishes with increasing number of weed plants, owing to an increased intra-specific competition of the weeds. This is reflected by the asymptotic shape of the curve (Fig. 1a).

A slightly different hyperbolic equation for crop yield loss from weeds was presented by Cousens, Peters \& Marshall (1984). They introduced an additional parameter to set the asymptote of the curve relating crop yield to weed density at a value unequal to zero.

The hyperbolic density response of equation (1) holds especially for total biomass yield. Within the plant density ranges usually considered, it also holds for the seed yield of many species. For some species, however, the relationship between seed yield and density shows a more parabolic shape (Holliday, 1960). Watkinson (1981), Spitters (1983b) and Firbank

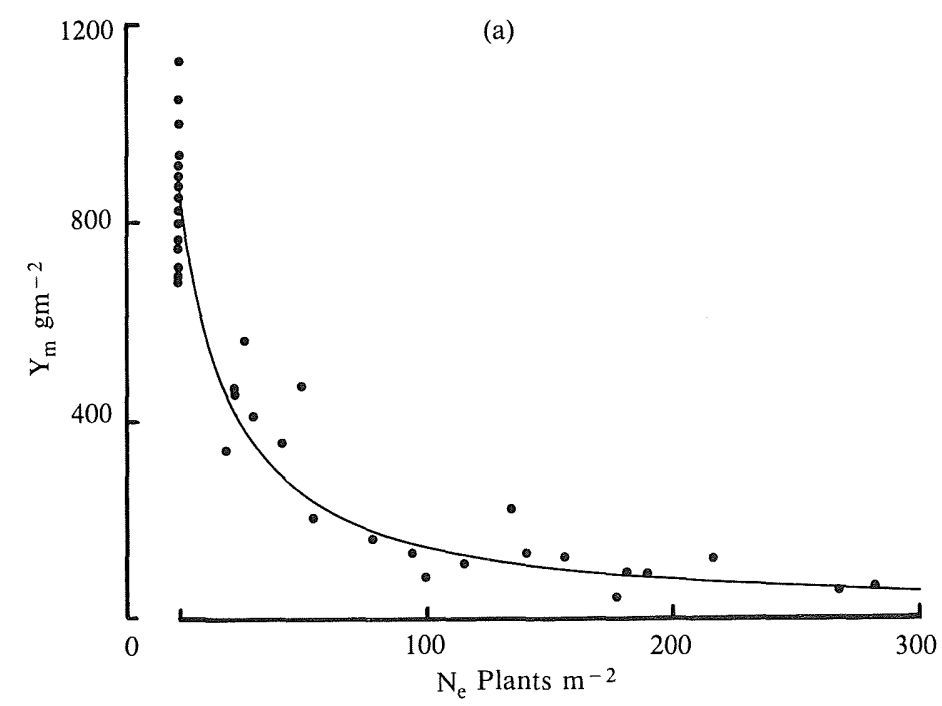




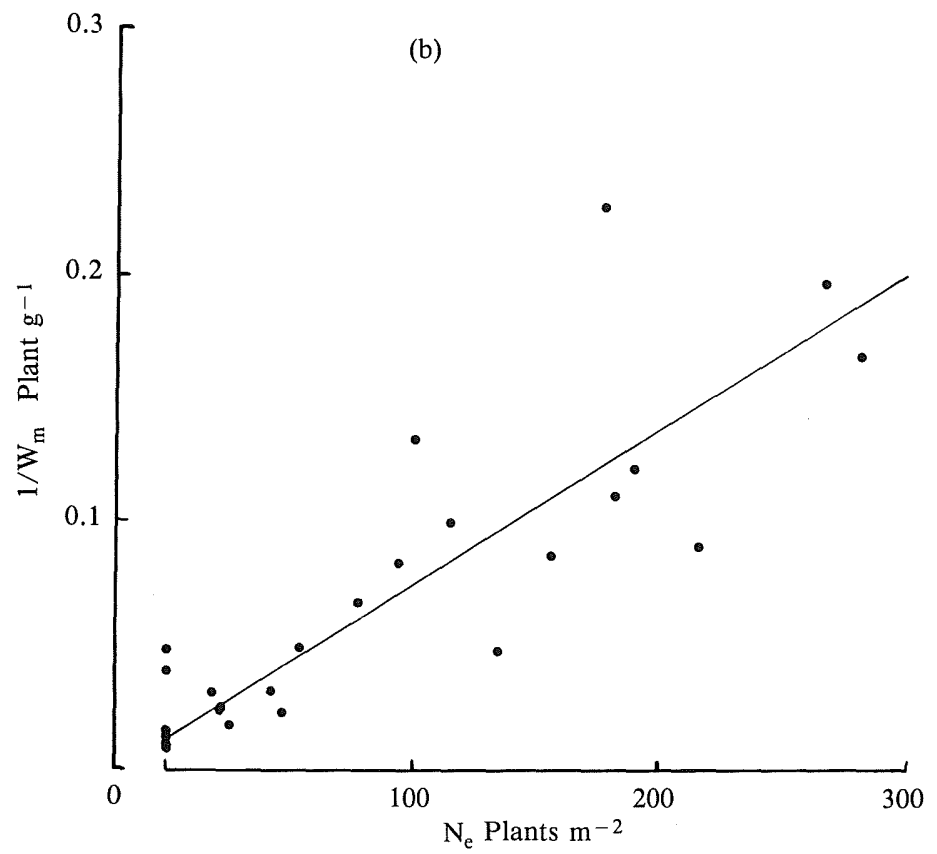

Fig. 1. Effect of Echinochloa density on (a) maize biomass per unit area, and (b) reciprocal of per-plant weight of maize. Relations were described by the regression $1 / \mathrm{W}_{\mathrm{m}}=0.0132+0.00058 \mathrm{~N}_{\mathrm{e}}$ and $\mathrm{Y}_{\mathrm{m}}=$ $11.1 \mathrm{~W}_{\mathrm{m}}$.

\& Watkinson (1985) presented parabolic extensions of the competition model by introducing one or more additional parameters. In many situations, however, the hyperbolic equation (3) is sufficient and the introduction of additional parameters is redundant and may result in imprecise estimates of the individual parameters due to over-parameterisation.

\section{Estimation of competition coefficients}

The competition coefficients can be estimated from the linearised form for $1 / \mathrm{W}$ (eqn $3 a$ ) by linear regression. However, when plant weights (W) are distributed normally, the reciprocals $(1 / \mathrm{W})$ show a skewed distribution and their variances increase with an increase in plant density (Fig. 1b). This heterogeneity of variances biases the estimation of the regression coefficients. Moreover, in competition studies, one has often to deal with a wide yield range and from general experience the standard deviation of plant weight $\left(\sigma_{\mathrm{w}}\right)$ tends to be proportional to the mean $\left(\mu_{\mathrm{w}}\right)$ rather than constant, and thus it can be shown also that $\sigma_{1 / \mathrm{w}}$ tends to change proportionally to $\mu_{1 / \mathrm{w}}$.

To account for heterogeneity of variances, a weighted regression could be applied, with the reciprocals of the variances used as weights (e.g. Steel \& Torrie, 1960, p. 180). This technique was applied in a modified form by Spitters (1984) to estimate the competition coefficients from eqn $3 a$. However, with present-day statistical packages, it is easier to estimate the competition coefficients directly from eqn $3 b$ by non-linear regression. Heterogeneity of variances must be taken into account. The above-mentioned proportionality between standard deviation and mean implies that yields are distributed log-normally. The regression coefficients are therefore estimated by using non-linear regression to fit the logarithm of yield to the logarithm of the right-hand side of eqn $3 b$.

\section{Experimental design}

Maize cv. LG11 was grown with and without a natural vegetation of weeds on a sandy 
soil at Wageningen in 1983. Plots were harvested at intervals to determine the time courses of dry matter production of maize and the weed species. Maize was grown at a spacing of $0.30 \mathrm{~m}$ between and within the rows. The naturally established weed vegetation was dominated by Echinochloa crus-galli (L.) P.B. and to a lesser extent by Chenopodium album (L.). The populations of these two species were maintained in the weedy plots, but other weeds were removed by hand. In the weed-free plots, all weeds were regularly removed by hand.

A split plot design with 4 blocks was used with 3 main plots (weed-free maize, maize with weeds, weeds without maize) and the harvest dates randomised as plots within the main plots. At the final harvest, however, 28 weed-free maize plots, 20 weedy maize plots, and 4 weed plots were harvested in order to test the statistical reliability of the model with a greater sample. Plots were $2 \mathrm{~m} \times 2 \mathrm{~m}$ in size of which the central part of $0.9 \mathrm{~m} \times 0.9 \mathrm{~m}$ was harvested. Dates of $50 \%$ plant emergence were 5 June for maize, 3 June for Echinochloa and 4 June for Chenopodium. Final harvest was on 20 September 1983.

To illustrate the variation between years, results are presented of a similar experiment carried out in 1982 at the same site, but with three, fixed weed populations $(100,200$ and 300 Echinochloa plants $\mathrm{m}^{-2}$ ) only. Tables and figures all refer to the 1983 experiment.

The different statistical procedures for estimation of the parameters were evaluated with the yields of the 28 weed-free and 20 weedy maize plots of the final harvest in 1983 experiment. Plant densities of the weed species were characterised by their initial numbers, counted 3 weeks after emergence. Plant mortality after this date was very small. The non-linear regressions were carried out with the statistical package Genstat (Payne et al., 1987).

\section{Results}

\section{Competition effects at final harvest}

The regression approach was first applied to the 1983 yields of the final harvest to validate the model for an extensive data set. Most of the variation in biomass of maize and Echinochloa was accounted for by the number of Echinochloa plants. Chenopodium, of which the growth was severely depressed, was not responsible for significant variation in maize and Echinochloa biomass which could not be accounted for by Echinochloa alone. Therefore, only Echinochloa is considered further. The same conclusion could be drawn from any of the three methods of fitting the model; Table 1 shows the results for the log-transformed model.

Ordinary (unweighted) linear regression of $1 / \mathrm{W}_{\mathrm{m}}$ on the weed density $\mathrm{N}_{\mathrm{e}}$ was inferior to the non-linear regressions: the model fitted less well $\left(\mathrm{r}^{2}\right.$ in Table 2$)$ and the residuals - being the differences between observed and expected values - showed a more heterogeneous distribution. Moreover, the linear regression resulted in a biased and inaccurate estimate of the intercept $\mathrm{a}_{0}$. The estimated weed-free maize yields were $844 \mathrm{~g} \mathrm{~m}^{-2}$ from the observed mean value and $808 \mathrm{~g} \mathrm{~m}^{-2}$ from the value estimated as $\mathrm{N}_{\mathrm{c}} / \mathrm{a}_{\mathrm{o}}$ according to the linear regression. The $95 \%$ confidence intervals of these values were $802-887 \mathrm{~g} \mathrm{~m}^{-2}$ and $520-1850 \mathrm{~g} \mathrm{~m}^{-2}$, respectively.

In applying non-linear regression, use of the log-transformed equation, assuming a normal distribution of the residuals of the log-transformed yields, was compared with use of the untransformed equation, assuming a normal distribution of the residuals of the untransformed yields per unit ground area. Use of the log-transformed equation was superior: the residuals were distributed more homogeneously and the method accounted for slightly larger proportion of the variation. Log-transformation resulted in a less precise estimate of $a_{0}-$ the parameter related to weed-free crop yield - but gave a more precise estimate of $b_{w}$ - the parameter related to crop yield loss (Table 2). Consequently, only results from fitting the log-transformed equation are discussed further. 
Table 1. Hyperbolic equations characterising the effect of number of Echinochloa plants per $m^{2}\left(N_{e}\right)$ and Chenopodium plants $\left(N_{c h}\right)$ on the reciprocal of the per-plant weight of maize $\left(1 / W_{m}\right)$ and Echinochloa $\left(1 / W_{e}\right)$. Plant weights are in $\mathrm{kg}$ plant ${ }^{-1}$. The squared correlation coefficient $\left(r^{2}\right)$ denotes the percentage of the variation in $1 / W$ that was accounted for by the weighted regression. Parameters fitted by non-linear regression, using log-transformed equation.

$\begin{array}{lrl} & \mathrm{r}^{2} & \text { D.F. } \\ 1 / \mathrm{W}_{\mathrm{m}}=13.2+0.58^{* *} \mathrm{~N}_{\mathrm{e}} & 93.5 & 46 \\ 1 / \mathrm{W}_{\mathrm{m}}=13.9+1.82^{* *} \mathrm{~N}_{\mathrm{ch}} & 81.0 & 46 \\ 1 / \mathrm{W}_{\mathrm{m}}=13.2+0.48^{* *} \mathrm{~N}_{\mathrm{e}}+0.29 \mathrm{~N}_{\mathrm{ch}} & 94.1 & 45 \\ & & \\ & & \\ 1 / \mathrm{W}_{\mathrm{e}}=196+4.1^{* *} \mathrm{~N}_{\mathrm{e}} & 65.8 & 18 \\ 1 / \mathrm{W}_{\mathrm{e}}=357+7.0^{*} \mathrm{~N}_{\mathrm{ch}} & 59.5 & 18 \\ 1 / \mathrm{W}_{\mathrm{e}}=195+3.8^{* *} \mathrm{~N}_{\mathrm{e}}+0.89 \mathrm{~N}_{\mathrm{ch}} & 66.7 & 17 \\ & & \\ \text { Slopes deviating significantly from zero at: *0.01<P<0.05, } & * * P<0.01\end{array}$

Table 2. Regression coefficients, as estimated according to different procedures, characterising the effect of the number of Echinochloa plants on the yield of maize. Standard errors are in brackets. The last column gives the percentage of the total variation in the transformed yields that was accounted for by the regression.

$\begin{array}{lccc}\text { Regression procedure } & \begin{array}{c}\mathrm{a}_{\mathrm{o}} \\ \text { plant kg-1 }\end{array} & \begin{array}{c}\mathrm{b}_{\mathrm{w}} \\ \mathrm{m}^{2} \mathrm{~kg}^{-1}\end{array} & \mathrm{r}^{2} \\ \text { Linear } & 13.74(3.75) & 0.618(0.042) & 82.7 \\ \text { Non-linear, untransformed } & 13.16(0.29) & 0.501(0.071) & 91.7 \\ \text { Non-linear, ln-transformed } & 13.19(0.59) & 0.580(0.041) & 93.5\end{array}$

The effect of Echinochloa density on biomass yield of maize and Echinochloa is depicted in Figs 1 and 2. The linear trends in Figs $1 \mathrm{~b}$ and 2 give support to the assumption that adding plants of the same species and of other species has an additive effect on the reciprocal of the per-plant weight, even at high densities.

In the experiment carried out in 1982, the competitive relations were completely different. At a density of 100 Echinochloa plants $\mathrm{m}^{-2}$, maize yield was reduced by $82 \%$ in 1983 (Fig. $1 a$ ), but by only $8 \%$ in 1982 . This was also reflected in the competition coefficients (eqn 5): $\mathrm{a}_{\mathrm{o}}$ $=13.2$ plant $\mathrm{kg}^{-1}$ and $b_{w}=0.58 \mathrm{~m}^{2} \mathrm{~kg}^{-1}$ in 1983, and $\mathrm{a}_{\mathrm{o}}=8.5$ plant $\mathrm{kg}^{-1}$ and $\mathrm{b}_{\mathrm{w}}=0.0074$ $\mathrm{m}^{2} \mathrm{~kg}^{-1}$ in 1982. The large difference between both years was due to the phenomenon that in 1983, in contrast to 1982, maize was unable to overtop Echinochloa in the mixture. This was likely caused by a later emergence of maize relative to Echinochloa in combination with a very dry growing season (further discussion by Spitters, 1984, and Kropff, Vossen \& Spitters 1984). These results illustrate very clearly the problems in generalising the results of one competition experiment to another and the size of variation that may be expected between years.

\section{Time course of the competition effects}

For each of the harvest dates, equation (4) was fitted to the data. There was no harvest where the inclusion of Chenopodium in the calculations improved the regression significantly, so again only Echinochloa was considered further.

The relative competitive effect of Echinochloa with respect to maize is characterised by the ration $\mathrm{b}_{\mathrm{e}} / \mathrm{a}_{\mathrm{o}}$ (subscript $e$ refers to Echinochloa. This ratio followed a more or less Sshaped curve with time (Fig. 3). Early in the growing season when inter-plant competition is still negligible, the value of the ratio $b_{e} / a_{o}$ is very small. The competition effects increase 


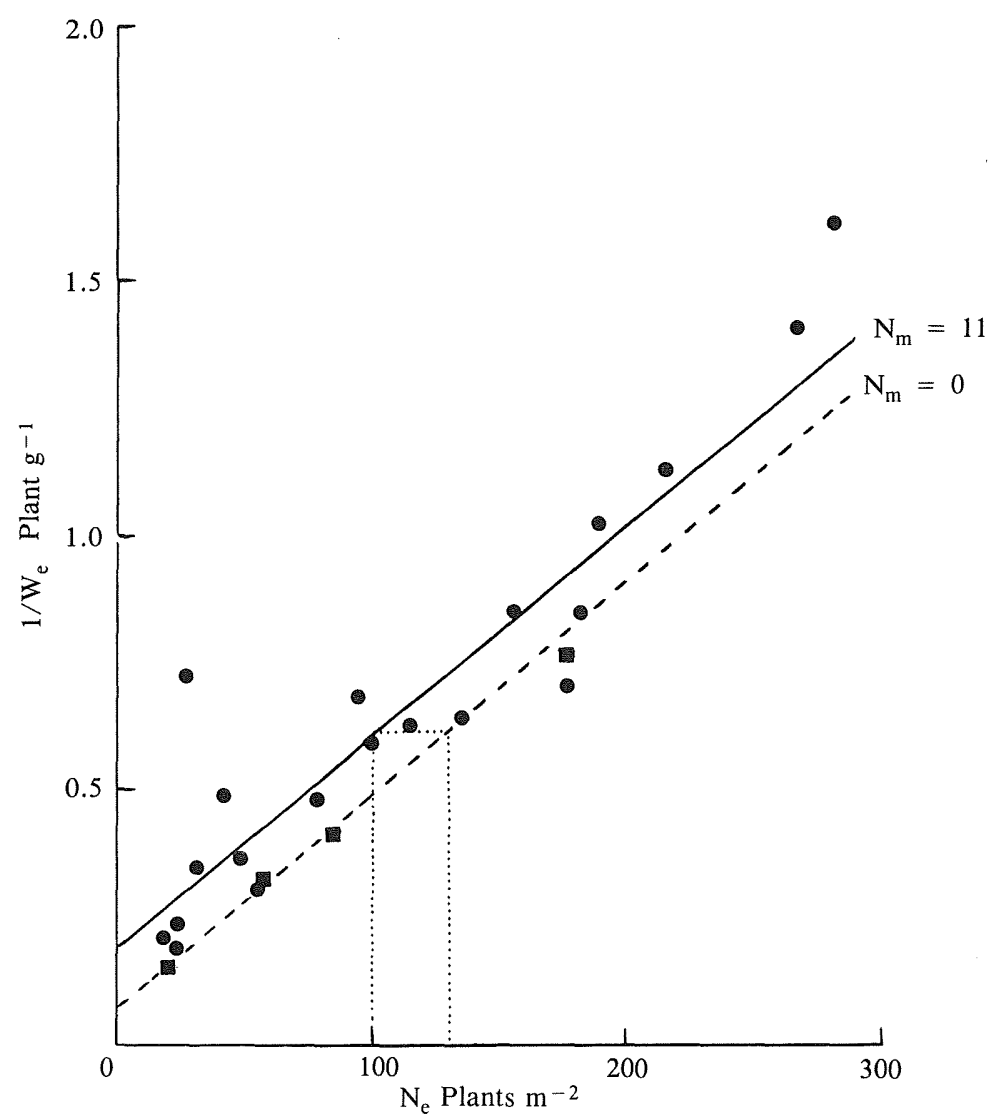

Fig. 2. Effect of Echinochloa density on the reciprocal of the per-plant weight of Echinochloa in plots without maize (, $\mathrm{N}_{\mathrm{m}}=0$ ) and in plots with maize $\left(, \mathrm{N}_{\mathrm{m}}=11\right.$ ). The dotted lines indicate that addition of 11 maize plants to a population of 100 Echinochloa plants $\mathrm{m}^{-2}$ had the same effect as adding 28 Echinochloa plants to that population. Regression equations were $1 / \mathrm{W}_{\mathrm{e}}=0.075+0.00416 \mathrm{~N}_{\mathrm{e}}$ for $\mathrm{N}_{\mathrm{m}}=0$, and $1 / \mathrm{W}_{\mathrm{e}}=0.196+0.00410 \mathrm{~N}_{\mathrm{e}}$ for $\mathrm{N}_{\mathrm{m}}=11$.

with time. The terminal data point is the most precise one, as it was based on 20 weed plots, while the other points were derived from four weed plots each.

The approach presented enables adjustment of the yield of the species for the heterogeneity in weed density among the plots. For any harvest, the yields of maize and Echinochloa were interpolated to a density of 100 Echinochloa plants $\mathrm{m}^{-2}$ by means of equation (4) on the basis of the fitted regressions. The time course of the dry weights (Fig. 4) illustrates the strong reduction of maize growth from the competition with Echinochloa.

\section{Discussion}

Model and parameter estimation. It has frequently been shown that a model based on the hyperbolic yield-density equation gives in many situations a good description of the competitive interactions between species in mixed vegetation. In this paper, it is demonstrated that such a model can also be useful in describing the seasonal course of crop growth reduction due to a naturally established weed population.

It is shown that in estimating the competition coefficients, special attention has to be paid 


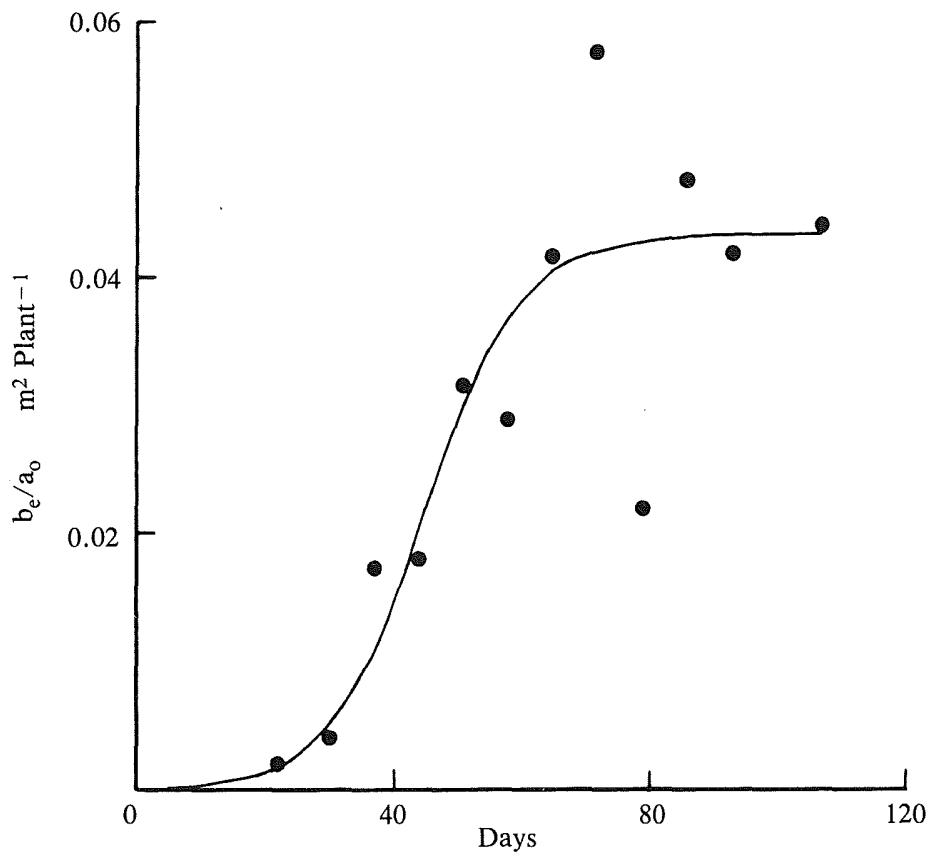

Fig. 3. Time course of the factor $b_{e} / a_{0}$, characterising the relative reduction in maize biomass due to the presence of Echinochloa. Time is in days after emergence of maize. Curve was fitted by a logistic function with data points weighted to the inverse of their variances.

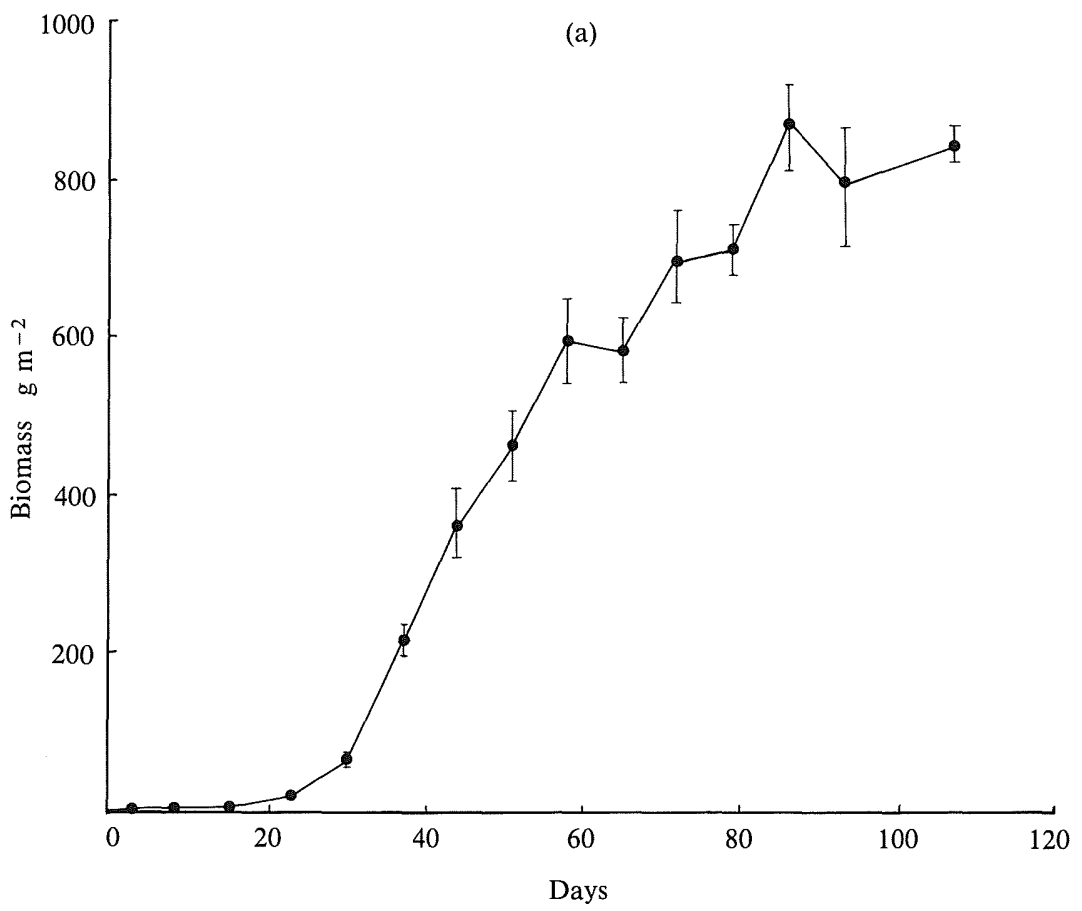




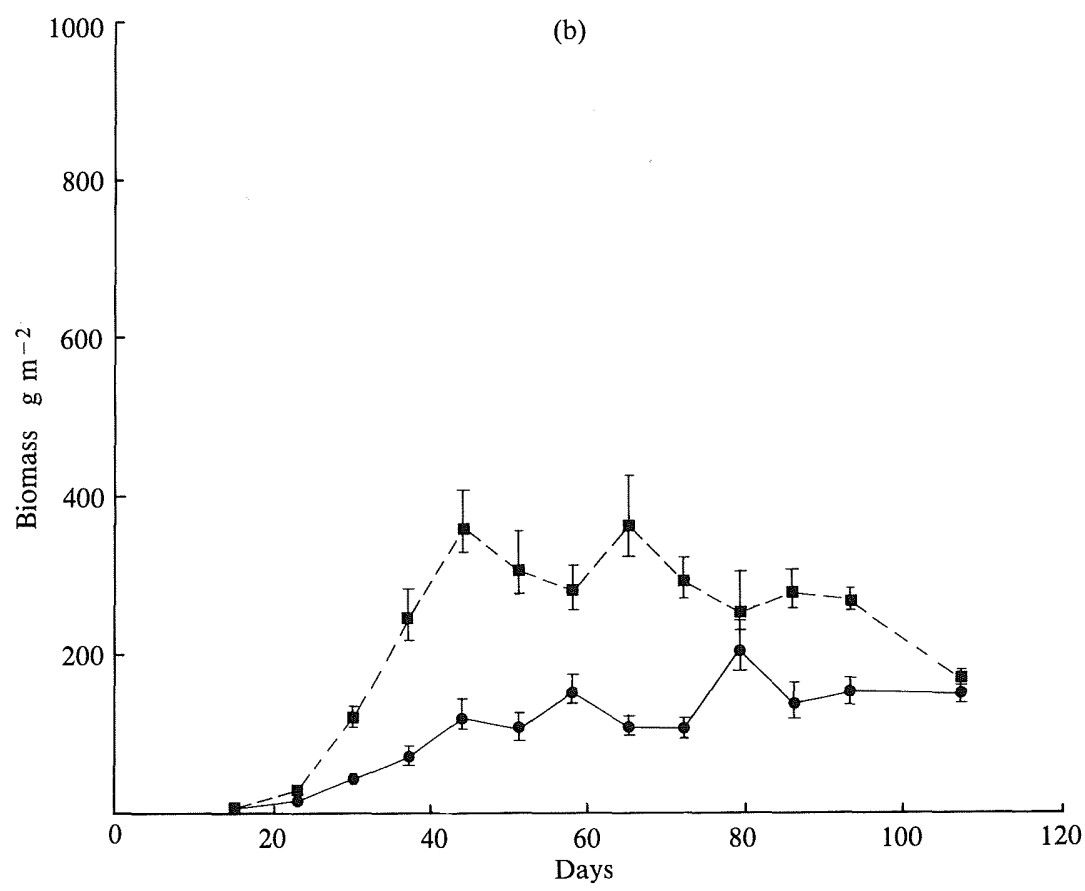

Fig. 4. Time course of the biomass production of maize (solid curves) and Echinochloa (broken curve) (a) in maize monoculture and (b) in mixture with a population of 100 Echinochloa plants per $\mathrm{m}^{2}$. Time is in days after emergence of maize. Bars represent $95 \%$ confidence intervals.

to the statistical requirement of homogeneity of variances. The model can be linearised by considering the reciprocal of yield and the coefficients can then be estimated by simple linear regression, but that introduces a large bias in the estimates - especially in those of $\mathrm{a}_{\mathrm{o}}-$ due to the heterogeneity of variances. Non-linear regression, using log-transformed data of yield per unit ground area, performed better.

Three possible fields of application of the competition model in weed research and control can be envisaged:

(1) Prediction of expected crop yield loss from weeds. Decision support models for weed control require an assessment of crop yield loss from weeds. Usually the assessment is tuned to a monitoring of the weed infestation early in the growing season in terms of the numbers of plants of the various weed species. Equation (5) can be used in forecasting the yield loss. Multi-species infestations are included by expanding the equation additively according to $\mathrm{N}_{\mathrm{w}} \mathrm{b}_{\mathrm{w}} / \mathrm{a}_{\mathrm{o}}=\mathrm{N}_{1} \mathrm{~b}_{1} / \mathrm{a}_{\mathrm{o}}+\ldots+\mathrm{N}_{\mathrm{m}} \mathrm{b}_{\mathrm{m}} / \mathrm{a}_{\mathrm{o}}$ for the weed species 1 to $\mathrm{m}$. The 'damage coefficient' $b_{i} / a_{0}$, i.e. the apparent initial yield reduction, has to be known for each weed species i and can be determined in separate competition experiments. Equation 5 is then considered as a new model with the damage coefficient and the weed-free crop yield as parameters to be estimated.

The magnitude of $b_{i} / a_{o}$ may vary strongly between years as was illustrated for the two field experiments with Echinochloa in maize. A large part of the variation in $b_{i} / a_{o}$ is probably explained by the variation in relative times of emergence of crop and weed. Instead of incorporating these times of emergence as an additional variable in equation (5), it is more convenient to characterise crop and weeds by their relative leaf area or soil coverage as recorded in the field early in the season. In equation (5), $\mathrm{N}_{\mathrm{w}}$ is replaced by the ratio of the leaf areas of weed and crop $\left(\mathrm{L}_{\mathrm{w}} / \mathrm{L}_{\mathrm{c}}\right)$ to forecast crop yield loss. 
(2) Prediction of the changes in weed seed populations. Forecasting long-term changes in weed populations draws upon models in which the dynamics of soil seed populations of the weeds are simulated over years. The effect of weed density on weed seed production may be taken into account by means of equation (5), which supplies an estimate of the biomass yields of the various weed species in relation to their plant density and competitive ability. Multiplication by the number of seeds produced per gram of biomass, which is rather constant for a species, gives the seed production of the species in that particular vegetation. In addition, equation (5) gives also an estimate of the concomitant crop yield loss (Spitters \& Aerts, 1983; Firbank et al., 1984; Spitters, 1989).

(3) Adjusting plot yields for the heterogeneity in weed population. Interpretation of the results from field experiments with naturally established weed populations is complicated by the heterogeneity in weed densities among the plots. Often it is assumed that replication of density is achieved and differences in estimated density are assumed to be due only to sampling error. In reality, plant densities usually vary greatly between plots, even in experiments where weeds are sown at specific seed rates. Thinning the weeds to constant plant densities is impractical. In this paper, it was shown that equation (3) can be used to interpolate plot yields to standard weed densities.

\section{References}

Cousens, R. (1985). A simple model relating yield loss to weed density. Annals of Applied Biology 107, 239-252.

Cousens, R., Peters, N. C. B. \& Marshall, C. J. (1984). Models of yield loss-weed density relationships. Proceedings of the 7th International Symposium on Weed Biology, Ecology and Systematics, COLUMA-EWRS, Paris, pp. 367-374.

Elberse, W. T. \& de Kruyf, H. N. (1979). Competition between Hordeum vulgare L. and Chenopodium album L. with different dates of emergence of Chenopodium album. Netherlands Journal of Agricultural Science 27, 13-26.

Firbank, L. G., Manlove, R. J., Mortimer, A. M. \& Putwain, P. D. (1984). The management of grass weeds in cereal crops, a population biology approach. Proceedings of the 7th International Symposium on Weed Biology, Ecology and Systematics, COLUMA-EWRS, Paris, pp. 375-384.

Firbank, L. G. \& Watkinson, A. R. (1985). On the analysis of competition within two-species mixtures of plants. Journal of Applied Ecology 22, 503-517.

Håkansson, S. (1983). Competition and production in short-lived crop-weed stands. Sveriges Lantbruksuniversitet Report 127, 85 pp.

Holliday, R. (1960). Plant population and crop yield. Field Crop Abstracts 13, 159-167, 247-254.

Kropff, M. J., Vossen, F. J. H. Spitters, C. J. T \& de Groot, W. (1984). Competition between a maize crop and a natural population of Echinochloa crus-galli (L.) P.B. Netherlands Journal of Agricultural Science 32, 324-327.

Payne, R. W., Lane, P. W., Ainsley, A. E., Bicknell, K. E., Digby, P. G. N., Harding, S. A., Leech, P. K., Simpson, H. R., Todd, A. D., Verrier, P. J., White, R. P., Gower, J. C., Tunnicliffe Wilson, G. \& Paterson L. J. (1987). Genstat 5 Reference Manual. Oxford: Clarendon Press, 749 pp.

Rerkasem, K. (1978). Associated growth of wheat and annual ryegrass and the effect on yield and yield components of wheat. Ph.D. Thesis, Dept of Agronomy, University of Western Australia, 212+182 pp.

Spitters, C. J. T. (1983a). An alternative approach to the analysis of mixed cropping experiments. 1. Estimation of competition effects. Netherlands Journal of Agricultural Science 31, 1-11.

Spitters, C. J. T. (1983b). An alternative approach to the analysis of mixed cropping experiments. 2. Marketable yield. Netherlands Journal of Agricultural Science 31, 143-155.

Spitters, C. J. T. (1984). A simple simulation model for crop-weed competition. Proceedings of the 7th International Symposium on Weed Biology, Ecology and Systematics, COLUMA-EWRS, Paris, pp. 355-366. 
Spitters, C. J. T. (1989). Weeds: population dynamics, germination and competition. In Simulation and Systems Management in Crop Protection. Eds R. Rabbinge, S. A. Ward and H. H. van Laar. Simulation Monographs, No. 32. Wageningen: Pudoc, pp. 182-216, 332-346, 379-392.

Spitters, C. J. T \& Aerts, R. (1983). Simulation of competition for light and water in crop-weed associations. Aspects of Applied Biology 4, 467-484.

Spitters, C. J. T. \& van den Bergh, J. P. (1982). Competition between crop and weeds: a system approach. In Biology and Ecology of Weeds. Eds W Holzner and M. Numata. The Hague: Junk Publications, pp. 137-148.

Steel, R. G. D. \& Torrie, J. H. (1960). Principles and Procedures of Statistics. New York: McGrawHill, $481 \mathrm{pp}$.

Suehiro, K. \& Ogawa, H. (1980). Competition between two annual herbs, Atriplex gmelini C. A. Mey and Chenopodium album L., in mixed cultures irrigated with seawater of various concentrations. Oecologia 45, 167-177.

Watkinson, A. R. (1981). Interference in pure and mixed populations of Agrostemma githago. Journal of Applied Ecology 18, 967-976.

Watkinson, A. R. (1984). Yield-density relationships: the influence of resource availability on growth and self-thinning in populations of Vulpia fasciculata. Annals of Botany 53, 469-482.

de Wit, C. T. (1960). On competition. Agricultural Research Reports (Verslagen Landbouwkundig Onderzoek) 66(8), $82 \mathrm{pp}$.

Wright, A. J. (1981). The analysis of yield-density relationships in binary mixtures using inverse polynomials. Journal of Agricultural Science, Cambridge 96, 561-567.

(Revised version received 21 July 1988) 